\title{
Analysis of SLC4A11, ZEB1, LOXHD1, COL8A2 and $T C F 4$ gene sequences in a multi-generational family with late-onset Fuchs corneal dystrophy
}

\author{
HUI TANG ${ }^{1,2}$, WEN ZHANG ${ }^{1}$, XIN-MIN YAN ${ }^{1}$, LIN-PING WANG ${ }^{1}$, \\ HONG DONG ${ }^{1}$, TAO SHOU ${ }^{3}$, HUO $\mathrm{LEI}^{4}$ and QIANG GUO ${ }^{1}$
}

\begin{abstract}
${ }^{1}$ College of Environmental Science and Engineering, Kunming University of Science and Technology, Kunming, Yunnan 650500;
${ }^{2}$ Institute of Clinical and Basic Medical Sciences, Key Laboratory for Birth Defects and Genetic Diseases,

The First People's Hospital of Yunnan Province; Departments of ${ }^{3}$ Oncology and ${ }^{4}$ Ophthalmology,

The First People's Hospital of Yunnan Province, Kunming, Yunnan 650032, P.R. China
\end{abstract}

Received July 23, 2015; Accepted March 31, 2016

DOI: $10.3892 / \mathrm{ijmm} .2016 .2570$

\begin{abstract}
The aim of the present study was to determine the genetic basis of a multi-generational family with late-onset (LO) Fuchs corneal dystrophy (FCD). Five FCD causal genes [solute carrier family 4, sodium borate transporter, member 11 (SLC4A11), zinc finger E-box binding homeobox 1 (ZEBI), lipoxygenase homology domains 1 ( $L O X H D 1)$, collagen, type VIII, alpha 2 (COL8A2) and transcription factor 4 (TCF4)], previously reported to be implicated in the pathogenesis of FCD, were screened. A total of 27 variants [including 22 known single nucleotide polymorphisms (SNPs) from the Single Nucleotide Polymorphism Database (dbSNP) and 5 variants absent from dbSNP] were detected in this FCD pedigree across the SLC4A11, ZEB1, LOXHD1 and COL8A2 genes as follows: i) 22 known SNPs from dbSNP, including 3 coding (p.R161R, p.S213S and p.T833T) and 11 non-coding variants of $S L C 4 A 11,2$ intronic SNPs of ZEB1 from dbSNP (rs220057 and rs220060), 1 intronic SNP of LOXHD1 from dbSNP (rs16939650), and 5 SNPs of COL8A2 from dbSNP (p.A35A, p.R155Q, p.L335L, p.G495G and p.T502M); and ii) 5 variants that have not been previously reported in FCD patients and that are absent from dbSNP were identified across the ZEBI and LOXHDI genes;
\end{abstract}

Correspondence to: Professor Huo Lei, Department of Ophthalmology, The First People's Hospital of Yunnan Province, 157 Jinbi Street, Kunming, Yunnan 650032, P.R. China

E-mail: 1764370681@qq.com

Professor Qiang Guo, College of Environmental Science and Engineering, Kunming University of Science and Technology, 727 South Jingming Road, Chenggong District, Kunming, Yunnan 650500, P.R. China

E-mail: gqkj003@sina.com

Key words: Fuchs corneal dystrophy, SLC4A11, ZEB1, LOXHD1, COL8A2, TCF4 these included 3 continuous indels located at the junction of the 5'-UTR and the adjacent exon 1 of ZEB1 [Indel 1 (c.-86_-53delins gggaggggtggaggcggaggggtGGGGGGGAAGG); Indel 2 (c.-52_-46delinsGGGAGGG); and Indel 3 (c.-45_-42delinsAGGG)], and 2 intronic variants of $L O X H D 1$ (c.5332-126C $>\mathrm{T}$ and c. $1809+155 \mathrm{G}>\mathrm{A})$. Apart from one intronic SNP of SLC4A11 from dbSNP (rs372201212), the pathologic consequence of which is uncertain, and 2 intron variants of LOXHDI (c.5332$126 \mathrm{C}>\mathrm{T}$ and $\mathrm{c} .1809+155 \mathrm{G}>\mathrm{A}$ ); the variants likely represent examples of de novo mutations. Neither of the other 24 variants provided strong evidence of pathogenesis in this FCD pedigree. An analysis of 7 SNPs in TCF4 from dbSNP, which have been associated with LO FCD in different populations, revealed that these 7 SNPs were not associated with FCD in this specific pedigree. A genome-wide linkage scan to search for linkage to one of the previously described FCD loci or to identify a novel locus for FCD will need to be performed in this FCD pedigree. Our observation, nevertheless, expands the knowledge of the genetic status of patients with FCD.

\section{Introduction}

Fuchs corneal dystrophy (FCD; MIM 136800), first described by Ernst Fuchs in 1910 (1), is characterized by bilateral primary corneal guttae and a reduced endothelial cell density that can result in corneal edema, discomfort and blurred vision (2). The onset of FCD generally occurs in the 4th decade of life onwards, and FCD progresses at a slow rate over the next 2 to 3 decades, causing severe impairment of endothelial cell function $(3,4)$, ultimately leading to severely impaired vision or blindness $(5,6)$. Currently, effective methods of restoring vision in advanced cases are corneal transplantation in the form of penetrating keratoplasty (PK) (7), Descemet's stripping endothelial keratoplasty (DSEK) (8) and Descemet's membrane endothelial keratoplasty (DMEK) (9).

FCD is genetically heterogeneous. To date, 4 loci, FCD1, FCD2, FCD3 and FCD4, on chromosomes 13, 18, 5 and 9 , respectively, along with numerous linkage peaks and susceptibility loci, have been localized through linkage 
analysis. In addition, 4 causal FCD genes, namely collagen, type VIII, alpha 2 (COL8A2) (MIM 12052) (4), solute carrier family 4, sodium borate transporter, member 11 (SLC4A11) (MIM 610206) (10,11), zinc finger E-box binding homeobox 1 (ZEB1) (MIM 189909) (12) and lipoxygenase homology domains 1 (LOXHDI) (MIM 613072) (13) have been identified, representing a small proportion of the total genetic load. Furthermore, a single nucleotide polymorphism (SNP) on chromosome 18q21, rs613872, in an intron of the transcription factor 4 (TCF4, MIM 602272) gene, which encodes a member of the E-protein family (E2-2), has been identified to be significantly associated with FCD; the association increased the probability of having FCD by a factor of 30 in individuals with 2 copies of the disease variants (homozygotes) and discriminated between case subjects and control subjects with approximately $76 \%$ accuracy (14). Another study that genotyped 18 SNPs within TCF4 in Singaporean Chinese revealed that the minor allele of rs613872 was not present in the genotyped cohort; 2 SNPs (rs17089925 and rs17089887) located upstream and in intron 3 of TCF4, respectively, were significantly associated with FCD; another 3 SNPs (rs1348047, rs1452787 and rs2123392) also exhibited a marginal association with FCD (15). Another TGC trinucleotide repeat expansion (rs193922902) within intron 3 of TCF4 has also been recently identified to be strongly associated with FCD, and a repeat length of $>50$ was determined to play a pathogenic role in the majority of FCD cases and is considered to be a predictor of disease risk (16).

As the susceptibility of genes to mutations can vary in different ethnicities and in view of the limited information on the genetics of FCD in southwestern China, we undertook this study. We screened for mutations in 4 causal FCD genes (SLC4A11, ZEB1, LOXHD1 and COL8A2) and genotyped 7 SNPs within the TCF4 gene to determine whether these known causal genes are responsible for causing FCD in this specific multi-generational late-onset (LO) FCD Chinese pedigree.

\section{Subjects and methods}

Case presentation. The study protocol was approved by the Ethics Committee of the First People's Hospital of Yunnan Province and was in compliance with the Declaration of Helsinki. Written informed consent was obtained from all study participants or their guardians. Family members of this LO FCD Chinese family were recruited through a proband with FCD (a 46-year-old woman) who presented to the Department of Ophthalmology, the First People's Hospital of Yunnan Province; extended pedigrees were subsequently developed through interviews. The age of the affected pedigree members in generation II and III ranged from 36 to 67 years.

A total of 191 individuals of Chinese ethnicity, consisting of 104 females and 87 males who ranged in age from 58 to 89 years with an average age of 68.6 (SD 6.9 years), who had a normal cornea upon ophthalmic examination and no history of any ocular disease in their family were recruited as healthy controls.

Clinical evaluation. All family members underwent a complete ophthalmic examination, including fundoscopy, a slit-lamp examination and specular microscopy, to document corneal guttae on December 2009. The diagnosis of FCD and the severity grading were based on a modified Krachmer scale, with grade 0 indicating an absence of guttae, grade 1 representing 12 or more central guttae, grade 5 denoting confluent central guttae with corneal edema, and grade 6 corresponding to disease severe enough to require keratoplasty (3). A detailed history was recorded for all subjects, including any family history and the duration of symptom onset.

DNA sample preparation. After obtaining written informed consent, peripheral blood samples were collected from the proband and her family members. Genomic DNA was extracted from the leukocytes of the peripheral blood using a cell/tissue genomic DNA extraction kit (BioTeke Corp., Beijing, China) according to the manufacturer's instructions. In addition, genomic DNA from 191 healthy individuals was extracted and used as the control DNA.

Sequencing analysis of SLC4A11, ZEB1, LOXHD1, COL8A2, and TCF4. A total of 69 sets of primers (Table I) were designed to completely incorporate the exon and intron boundaries of the SLC4A11 (NM_032034.3), ZEB1 (NM_030751.5), LOXHDI (NM_144612.6) and COL8A2 (NM_005202.3) genes, and all primers were designed such that they would be positioned on intronic segments at least 80 nucleotides on either side of the intron-exon boundary, to ensure complete reading of the exons. Primers were also designed to amplify the fragment of the TCF4 gene containing 7 SNPs. Polymerase chain reaction (PCR) was carried out with $25 \mathrm{ng}$ of genomic DNA as a template in a mixture of PCR buffer, $2.5 \mathrm{mM} \mathrm{MgCl}$, $0.2 \mathrm{mM}$ of each dNTP, $0.4 \mu \mathrm{M}$ of each primer, and 0.75 units of rTaq DNA polymerase (Takara Bio, Dalian, China). After an initial denaturation step at $95^{\circ} \mathrm{C}$ for $5 \mathrm{~min}, 35 \mathrm{PCR}$ cycles were performed as follows: $95^{\circ} \mathrm{C}$ for $30 \mathrm{sec}, 60^{\circ} \mathrm{C}$ for $30 \mathrm{sec}$, and $72^{\circ} \mathrm{C}$ for $1 \mathrm{~min}$, followed by a final extension at $72^{\circ} \mathrm{C}$ for $5 \mathrm{~min}$. The PCR-amplified products were purified and sequenced on an ABI 3130 Genetic Analyzer using the BigDye Terminator Cycle Sequencing v3.1 kit (Applied Biosystems Life Technologies, Foster City, CA, USA) according to the manufacturer's instructions. Sequence assembly and analysis were performed using the DNASTAR Lasergene.v7.1 program (DNAstar Inc., Madison, WI, USA).

Strand-specific sequencing. To confirm the indels we observed as mixed sequences, the 2 alleles were cloned so they could be sequenced separately. Fragments containing insertion or deletion alleles were amplified as described above and subcloned within the pZeroBack/blunt vector by using ZeroBack Fast Ligation kit (Tiangen Biotech Co., Ltd., Beijing, China), according to the instructions provided by the manufacturer. Plasmid DNA was isolated using the MiniPrep kit (Qiagen China Co., Ltd., Shanghai, China), followed by bidirectional sequencing according to the method described above, with a pZeroBack/blunt forward primer, 5'-CGACTCACTATA GGGAGAGCGGC-3' and reverse, 5'-AAGAACATCGA TTTTCCATGG CAG-3'.

Short tandem repeat (STR) assay. For TGC trinucleotide repeat expansion analysis of the TCF4 gene, a 5'-FAM-conjugated forward primer corresponding to a location upstream of the STR 
Table I. Primer sequences used to amplify exons of the $S L C 4 A 11, Z E B 1, L O X H D 1$ and $C O L 8 A 2$ genes, and 7 fragments containing 7 SNPs within the TCF4 gene.

\begin{tabular}{|c|c|c|c|c|c|}
\hline Gene & Exon & Forward primer $\left(5^{\prime} \rightarrow 3^{\prime}\right)$ & Reverse primer $\left(5^{\prime} \rightarrow 3^{\prime}\right)$ & $\begin{array}{l}\text { Product } \\
\text { size (bp) }\end{array}$ & $\begin{array}{l}\text { Coding } \\
\text { region } \\
\text { size }(b p)\end{array}$ \\
\hline \multirow[t]{11}{*}{ SLC4A11 } & 1 & GCCCGGTCCCTTCCTCTC & GCCAAAAGCATTCCAGCACTAG & 553 & 136 \\
\hline & 2,3 & CGGCTAGGGAATGCTGGAGA & GGAGCAGCGGGAGGATTCT & 631 & 153,50 \\
\hline & 4,5 & CCCGCTGCTCCCCTCTTC & GCAGTGCTCCAGCCCTCTTC & 720 & 232,82 \\
\hline & 6 & GGCGGCCCAACCAACTT & CCGCGTGTTTGAATAGGGATAG & 556 & 124 \\
\hline & $7,8,9 \mathrm{~A}$ & GGGGAGAGCACCTTCACCTG & CCCCGTCTGTGTTCTCGTCA & 688 & $219,94,126$ \\
\hline & $9 \mathrm{~B}, 10,11$ & TCCCCAGCAAACCCTCTCTC & TGGGGCAGCAATATGGTGG & 687 & 114,133 \\
\hline & 12 & TGCGCTTTATGCCTTTTTCAA & CACGGGCACACACTCAGCTT & 493 & 74 \\
\hline & $12,14,15 \mathrm{~A}$ & CCCCCTGGAGCCCTTTCT & GGCGGCCACCAAGTTCTG & 755 & $253,107,169$ \\
\hline & $15 \mathrm{~B}, 16,17 \mathrm{~A}$ & TCCGGGAAATCGAGAGTGAGT & AGCGCGATGTAGAGGAAGAGG & 791 & 174,196 \\
\hline & 17B, 18 & GCCGTGGACCCTGAGGAGT & CCCGCCCATTCTCCACAC & 617 & 170 \\
\hline & 19 & TGGGCTGGGATGGGTGTC & GGCAGTAGCAGGGACACAGGT & 537 & 70 \\
\hline \multirow[t]{12}{*}{ ZEB1 } & 1 & CCGCCCGGTCCCTAGCAACAAG & CGGAGGGGGGCAGAGAGCACTACTT & 413 & 58 \\
\hline & 2 & TTGCTGTTAAAATCCTGGCTCTG & TCCTTCCACTCAGCCATACTTTG & 1,115 & 20 \\
\hline & 3 & TCCTTTTCAGATTTCGGGAAGTT & TGATTCTCGTTTGCTGTGACATG & 789 & 60 \\
\hline & 4 & GGGGCTGTCTATTGTCCAACTTT & AAGGCAGATTCAGGAAAACCACT & 994 & 162 \\
\hline & 5 & AGCCCGTATTTGAACCCTGACT & TTCCATTGAGGGCTGAGTTGTC & 512 & 203 \\
\hline & 6 & CAAAACAACCATCAGGCTCACA & TTCACTCCСТCTCATTGCCTCTA & 674 & 106 \\
\hline & $7 \mathrm{~A}$ & CAGTTCTGTCACAAGCATGCATG & TGGCTAGGCTGCTCAAGACTGT & 791 & $1,811^{\mathrm{a}}$ \\
\hline & $7 \mathrm{~B}$ & CCCATTACAGGCAACCAGTTCT & TGGGGTTCATTTGCATTTGC & 876 & \\
\hline & $7 \mathrm{C}$ & TGAAAAGATGCAAGCTGGACAG & GGCTGGATCACTTTCAAGGGT & 702 & \\
\hline & $7 \mathrm{D}$ & GGCCATTGCTGACCAGAACA & GGTTCACAGCCACACTTCCTCAT & 743 & \\
\hline & 8 & TTCGGTGTCCTTGCTTTCTTTC & GCCGAGATTGAGATTGCGTG & 640 & 181 \\
\hline & 9 & ААСССТССССТТТСТАСААСАТG & GGCACACCCGGATTTATTTTG & 900 & 593 \\
\hline \multirow[t]{26}{*}{ LOXHD1 } & 1 & AGAAGGCAGAGGGAACA & ATGGGATAATCAGTGAGGAA & 439 & 130 \\
\hline & 2 & GTTGTGCTGGAAAGATTAC & CTGGTCCCTGGTGAGA & 844 & 115 \\
\hline & 3 & ТTCСТССТССАТССАС & СААТСССТСАСТТТСАТС & 508 & 81 \\
\hline & 4 & ACCGAGGTTCAGGAGA & GCAAGACAGGCACGA & 405 & 185 \\
\hline & 5 & GGGGTAAGTGTAGATGGTG & TTCTTGCTTTCCCTGTG & 650 & 99 \\
\hline & 6 & AAGGAAGTCTGTAGGCTGAA & CTGGCTTAGGTAGAAGAGTGG & 657 & 149 \\
\hline & 7 & AAGGTAATCGCCAGTCA & TTCAGGAGCAGGAGGA & 473 & 124 \\
\hline & 8 & ATTCTTAGCCAACCCG & GGATAATCATAACCACCAA & 822 & 251 \\
\hline & 9,10 & TGGGTGATACCTACTTTG & АТСССТТССТССТТТС & 1,116 & 136,161 \\
\hline & 11,12 & GTTTATTGCTTGGAGGAT & ACTTGGAGATGGCTTTT & 1,127 & 87,136 \\
\hline & 13 & GGAAGGTCAGCCCAGAT & TCCCAGGAGTCCAACAG & 546 & 155 \\
\hline & 14 & GAGCAGGATGTTGTGG & AGTAGGGCTGGGTCTT & 913 & 161 \\
\hline & 15 & TCCAATCTCAGCCAAAC & GCACAGGCAGGAACTCT & 452 & 77 \\
\hline & 16 & ATTTACACGCTTTCCTG & TCTTAGTCCTCCСТTCTC & 857 & 197 \\
\hline & 17 & ССССТСТTGTТTСТСАС & CATTGGGTCCTCAGTTT & 677 & 193 \\
\hline & 18 & GCTGGTATGTGACTCCTC & GATTTGCCTGGTATGG & 737 & 161 \\
\hline & 19,20 & CTGGCTCTTTGTTGGG & TGTTTGTTCCTGTGGGT & 1,423 & 463,155 \\
\hline & 21 & TCCAGCAAACCTATCTTC & GTCTTCTTCCAGGACTACC & 513 & 134 \\
\hline & 22 & CAGGCAAATGACTAATGG & GAGGGAAGGAAGATGGA & 428 & 164 \\
\hline & 23 & GGGCTCACAGATACAGG & GACCCAACACTAAACACC & 640 & 105 \\
\hline & 24,25 & AACTCACCCATGTAACCA & CAGGGATGAAAGACCAA & 1,441 & 129,165 \\
\hline & 26 & GGGATACGGAGAAGAGTG & AGGAGGAGCAGGGTGAG & 897 & 182 \\
\hline & 27,28 & GGCAAGACAGGAGCAT & GGACGAGGATAAACCAG & 1,984 & 117,163 \\
\hline & 29 & TGGCAGGTAGATTTAGTGA & AGGGCAAGGGCAGA & 661 & 155 \\
\hline & 30,31 & GAGTGGGTTGAGTGGG & ATCGGTGATGGTGGG & 608 & 210,136 \\
\hline & 32 & GAAACCTACCCAACAATG & GTGGCTCACCCAAAGT & 1,003 & 209 \\
\hline
\end{tabular}


Table I. Continued.

\begin{tabular}{|c|c|c|c|c|c|}
\hline Gene & Exon & Forward primer $\left(5^{\prime} \rightarrow 3^{\prime}\right)$ & Reverse primer $\left(5^{\prime} \rightarrow 3^{\prime}\right)$ & $\begin{array}{l}\text { Product } \\
\text { size (bp) }\end{array}$ & $\begin{array}{l}\text { Coding } \\
\text { region } \\
\text { size (bp) }\end{array}$ \\
\hline & 33 & GCCTGGACTTAGGTTGG & GAAGAAATGTTATGGGTAGA & 657 & 128 \\
\hline & 34 & GCAGCATTACCTTCTATTT & AAGCCAGAGGAACCAG & 786 & 118 \\
\hline & 35 & GCAAATGTCAGCGTTCT & GTTGGAGTGGTAAGGGA & 601 & 175 \\
\hline & 36 & AACTTCCCTGCTTCCT & AACACTGGCTCTTTCATAC & 743 & 186 \\
\hline & 37 & CTCTGAGACCACCTAACC & ACAAGCCTCTTCCAATC & 879 & 171 \\
\hline & 38 & CTACCTACAACGCCTCAA & TGGGCATCCGAACAG & 620 & 133 \\
\hline & 39 & AAATGCTTACCTGCTTCA & TCTGGTCCCTACTCTGC & 646 & 159 \\
\hline & 40 & CCAAGTAGCAGGAGGG & TTGCCACTGGGTTTATT & 1,449 & 699 \\
\hline \multirow[t]{5}{*}{ COL8A2 } & 1 & CCCCGCGACTTTGAAAATTG & GGGCGCCTGAGGATCTGAT & 470 & 193 \\
\hline & $2 \mathrm{~A}$ & СССАTTCTTCCTCTCCCGTGTA & TTGCCTAAGCCAGCTGGACC & 630 & $1,919^{\mathrm{a}}$ \\
\hline & $2 \mathrm{~B}$ & GGCCTCAAGGGGGATAATGG & TTTCCCAGCCAGGCCACTAG & 606 & \\
\hline & $2 \mathrm{C}$ & GGGCTTCCTGGCAGACGTG & CGGTGTGGCATGGGCAGA & 627 & \\
\hline & $2 \mathrm{D}$ & TGGGGCCTTCGATGAGACTG & GCCGCCTCTGTTCAGCTTTT & 624 & \\
\hline \multirow[t]{8}{*}{ TCF4 } & Including rs613872 & CCCAGGCACTCCCCATTTACT & GGACGTTGAACAGCTTGACAGG & 579 & \\
\hline & Including rs17089925 & TTCCTGCTTCTGACCC & AGTGACCTGCTTGCTC & 924 & \\
\hline & Including rs17089887 & GCATAGAAGGCAAGA & GTAAGGAAGAGGCAAT & 972 & \\
\hline & Including rs1348047 & GGGAATCATAAGCACG & GGCGAAAGGTAGCG & 576 & \\
\hline & Including rs 1452787 & GAATGGGAATCAAATAG & GCAAACTGTGGGAGG & 760 & \\
\hline & Including rs2123392 & AAGAATGTCAGGGAAAG & CAGAATCACTGCGAAA & 960 & \\
\hline & $\begin{array}{l}\text { Including rs } 193922902 \\
\text { (TGC repeat) }\end{array}$ & CAGATGAGTTTGGTGTAAGATG & ACAAGCAGAAAGGGGGCTGCAA & $230+(\mathrm{TGC}) 12-100$ & \\
\hline & $\begin{array}{l}\text { 5-FAM-TCF-Fuchs, } \\
\text { including rs } 193922902 \\
\text { (TGC repeat) }\end{array}$ & FAM-CAGATGAGTTTGGTGTAAGATG & ACAAGCAGAAAGGGGGCTGCAA & & \\
\hline
\end{tabular}

${ }^{a}$ Exons were amplified as multiple fragments because of their large size. SNPs, single nucleotide polymorphisms.

region was used in PCR as previously described (16) (Table I). Following PCR, $2 \mu \mathrm{l}$ of DNA were mixed with $12 \mu \mathrm{l}$ of diluted Map Marker 1000 (BioVentures, Inc., Murfreesboro, TN, USA). The gene scan was carried out using an ABI 3130 Genetic Analyzer (Applied Biosystems Life Technologies).

Statistical analysis. Statistical analysis was performed using the SPSS 16 software package. A $\chi^{2}$ test and Fisher's exact test were performed to compare the minor allele frequency (MAF) between data from the 1000 Genomes database and the Chinese healthy controls tested in the present study.

\section{Results}

Findings on ocular examination. Microscopic investigation of the proband II-9, a 46-year-old woman, revealed the pleomorphism of corneal endothelial cells and the presence of corneal guttae in both eyes of the proband at her first presentation to our hospital on December 2009 (Fig. 1). A 5-generation Chinese pedigree with 8 affected individuals was subsequently assembled through interviews with the initial proband (Fig. 2, arrow). FCD was diagnosed using slit-lamp biomicroscopy and assigned severity grades as described in the Subjects and methods (Fig. 2). The presence of an age-severity profile in this family was found to be generally consistent with that of LO FCD, which typically progresses from onset to end-stage disease over a period of approximately 2 decades $(17,18)$. Those affected in generation II, whose aged ranged from 56 to 67 years, all exhibited advanced advanced FCD (II-1, II-3, and II-5 all had grade 6 FCD; II-7 had grade 5 FCD), whereas in generations II and III, the affected individuals ranged in age from 36 to 46 years and typically had grades 3 and 4 disease (II-9 had grade 4 FCD; III-7, III-9, and III-19 all had grade 3 FCD) (Fig. 2).

Genetic analysis

Analysis of SLC4A11 gene. A total of 14 known variants (3 coding and 11 non-coding variants) from the Single Nucleotide Polymorphism Database (dbSNP) were detected in our analysis of the SLC4A11 gene (Table II). The 3 coding variants were synonymous variants that have been previously reported in Asian FCD cases and controls, namely, p.R161R (rs3827075, MAF: $\mathrm{G}=0.4798 / 2402)$, p.S213S (rs3803956, MAF: $\mathrm{T}=0.1663 / 833)(19,20)$, and p.T833T (rs58757394, MAF: $\mathrm{T}=0.0901 / 450$ ) (20) (Fig. 3A). All 3 variants were detected in both the affected members of this FCD pedigree (p.R161R, 5/16; 

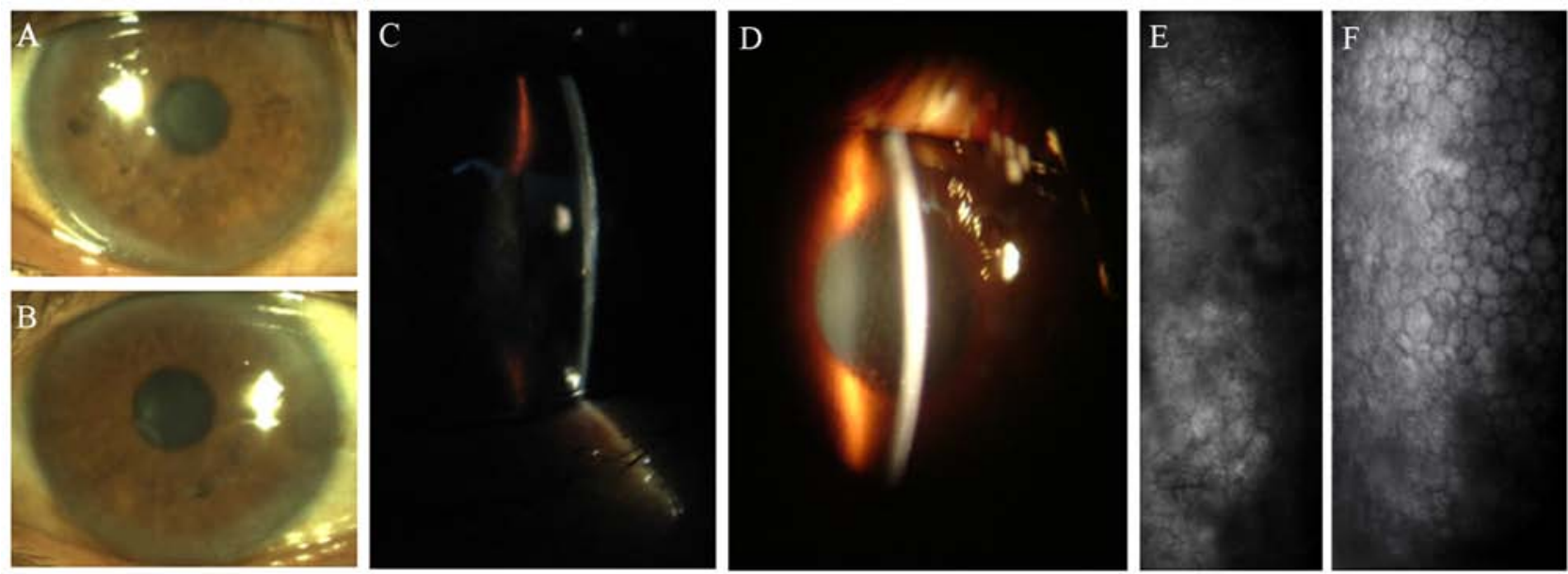

Figure 1. Clinical features of proband with late-onset (LO) Fuchs corneal dystrophy (FCD). (A and B) A clinical image shows severe corneal guttae caused by FCD, with an associated loss of corneal clarity in both (A) right and (B) left eyes. (C and D) Slit-lamp image of the corneal guttae were observed in both the (C) right and (D) left eyes. (E and F) Specular microscopy of the both the (E) right and (F) left eyes revealed pleomorphism of the corneal endothelial cell and corneal guttae (proband was 46 years of age when the microscopic investigation performed in December 2009).

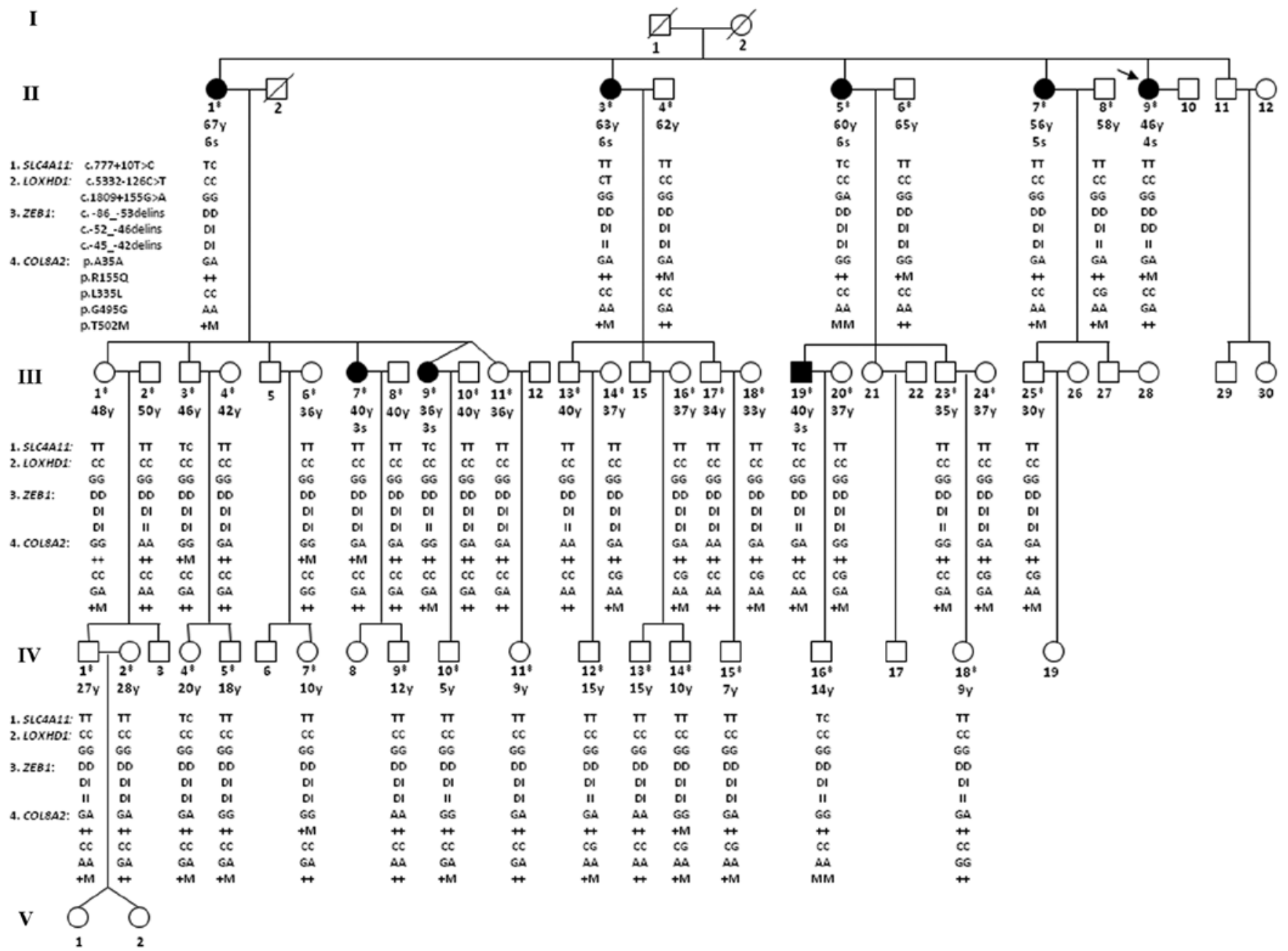

Figure 2. Pedigree of a Chinese family with late-onset (LO) Fuchs corneal dystrophy (FCD) with genotypes of 11 variantions identified across the SLC4A11, LOXHD1,ZEB1 and COL8A2 genes. Squares, males; circles, females; diagonal lines, deceased; filled symbols, affected individuals; unfilled symbols, unaffected individuals or not known to be affected; arrowhead, the proband. The double cross symbol indicates individuals in whom DNA collection and genetic analysis were performed, age is presented in years (y) and a severity grade is indicated for affected and unaffected individuals examined in detail in December 2009. Genotypes of 11 variantions identified across the $S L C 4 A 11, L O X H D 1, Z E B 1$ and COL8A2 genes are shown below the individual symbols in the following order: i) SLC4A11: c.777+10T>C (rs372201212); ii) LOXHD1: c.5332-126C >T and c.1809+155G >A; iii) ZEB1: Indel1, Indel2 and Indel3; and iv) COL8A2: p.A35A, p.R155Q, p.L335L, p.G495G and p.T502M. Genotypes of 3 intronic variations (SLC4A11: c.777+10T>C; and LOXHD1: c.5332-126C >T and c.1809+155G >A) and 3 synonymous variations of COL8A2 (p.A35A, p.L335L and p.G495G) are shown in alleles. Three indels of ZEB1 (Indel 1, Indel 2 and Indel 3) are showed as: D, deletion; I, insertion. Two missense variations of COL8A2 (p.R155Q and p.T502M) are shown as: +, wild-type; M, missense mutation. 


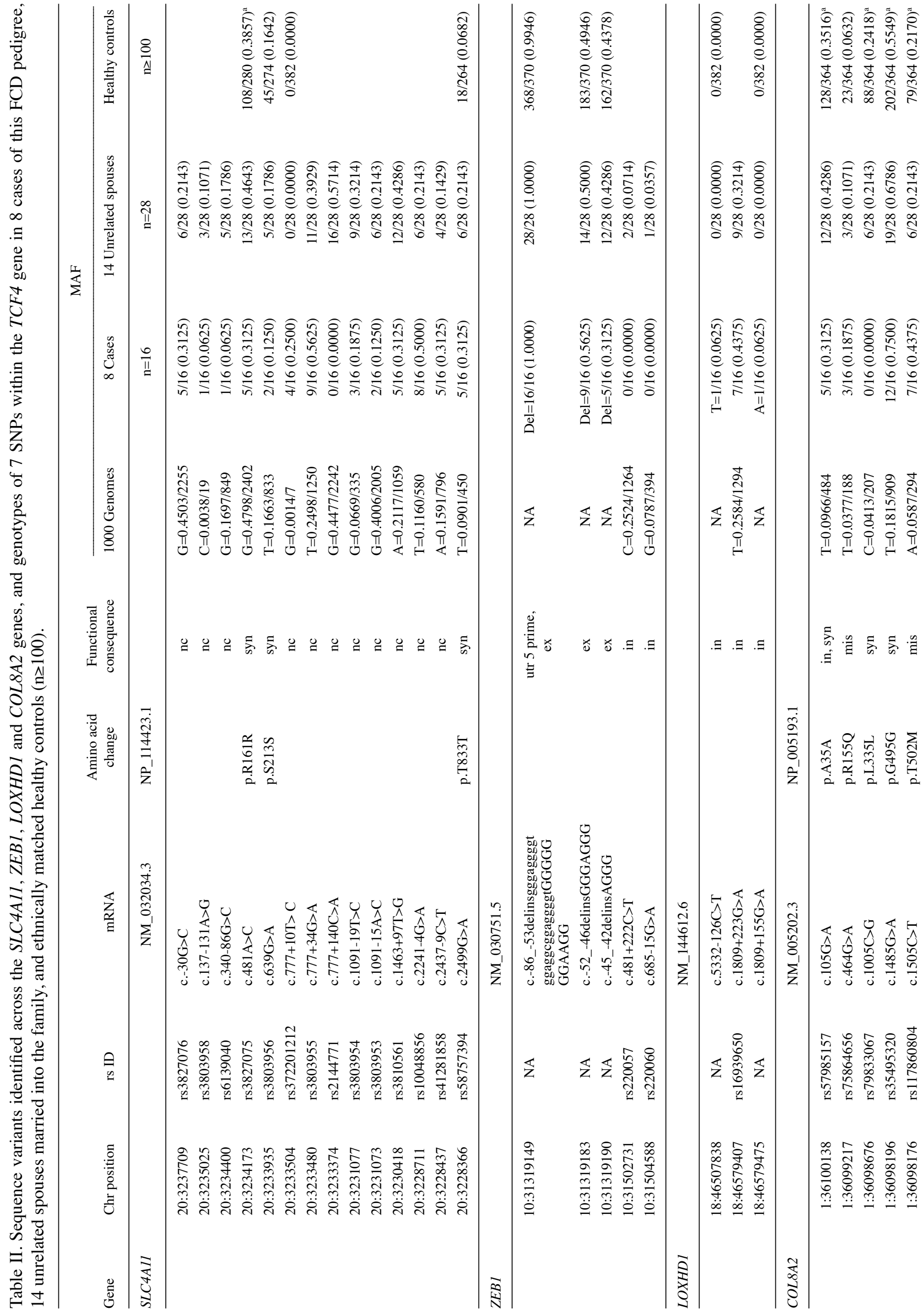


p.S213S, 2/16; and p.T833T, 5/16) and in 14 unaffected spouses who married into this family (the 14 spouses in whom DNA collection and genetic analysis were performed; p.R161R, 13/28; p.S213S, 5/28; and p.T833T, 6/28), as well as in unrelated, ethnically matched, healthy control subjects $(\mathrm{n} \geq 100)$ (Table II).

Among the 11 non-coding variants identified in this FCD pedigree, 9 variants (rs3827076, rs3803958, rs6139040, rs3803955, rs3803954, rs3803953, rs3810561, rs10048856 and rs41281858) were detected in both the affected members of this FCD pedigree and in 14 unaffected individuals who married into this family. As for rs2144771, it was absent in the 8 affected members of this FCD pedigree (0/16), whereas it was detected in the 14 unaffected individuals who married into this family (16/28) (Table II). For an intronic variant (rs372201212, MAF: $\mathrm{G}=0.0014 / 7)$, its minor allele $(\mathrm{G})$ was detected in 4 of the 8 affected members of this FCD pedigree, II-1, II-5, III-9 and III-19 (4/16), and in 3 of 20 healthy descendants in this family (in whom DNA collection and genetic analysis were performed), III-3, IV-4 and IV-16 (3/40). This variant was absent in the other 4 affected members of this FCD pedigree (II-3, II-7, II-9 and III-7). As this variant was not identified in the 14 unaffected individuals who married into this family (0/28) (Table II) (Fig. 2), this variant was further tested in unrelated ethnically matched controls $(\mathrm{n} \geq 100)$, and the results revealed that it was also absent in the 191 healthy samples we tested (0/382) (Table II).

Analysis of ZEB1 gene. Bidirectional sequencing of the PCR product encompassing the 5'-UTR region and exon 1 of the ZEBI genomic DNA (GenBank reference ID: NC_000010.11) of the proband (II-9) of this pedigree revealed a homozygous $34 \mathrm{bp}$ deletion involving $23 \mathrm{bp}$ of the 5'-UTR region and the adjacent $11 \mathrm{bp}$ at the $5^{\prime}$ end of exon 1 (GenBank reference ID: NM_030751.5): c.-86_-53delins gggaggggtggaggcgg aggggtGGGGGGGAAGG (exon and 5'-UTR sequences are depicted by capital and lower case letters, respectively), as well as a heterozygous $7 \mathrm{bp}$ indel in exon 1: c.-52_-46delins GGGAGGG. Follow-up screening of the other family members of this specific FCD pedigree revealed that there was another 4 bp indel: c.-45_-42delinsAGGG (Fig. 4A). These 3 indels were named Indel 1, Indel 2 and Indel 3; however, these 3 indels were present in both the affected members of this FCD pedigree (Indel 1: Del, 16/16; Indel 2: Del, 9/16; and Indel 3: Del, 5/16) and in the 14 unaffected individuals who married into this family (Indel 1: Del, 28/28; Indel 2: Del, 14/28; Indel 3: Del, 12/28) (Table II) (Fig. 2), as well as in the unrelated, ethnically matched, healthy control subjects (Indel 1: Del, 368/370; Indel 2: Del, 183/370; Indel 3: Del, 162/370) (Table II).

To further characterize the indels observed, 8 cases (II-1, II-3, II-5, II-7, II-9, III-7, III-9 and III-19), 3 healthy individuals who married into the family (II-4, II- 6 and II- 8 ), 2 healthy descendants of the family (III-11 and III-23) and 7 healthy control subjects (H4, H22, H31, H67, C8, C30 and C52) were enrolled in the validation set. PCR products of the segment encompassing the 5'-UTR region and exon 1 of the ZEBI gene were then subcloned into a pZeroBack/blunt vector. Plasmids were extracted from 10-20 positive colonies in each sample and sequenced bidirectionally by ABI 3130 , according to the method described above. Subsequent sequence analysis demon- 

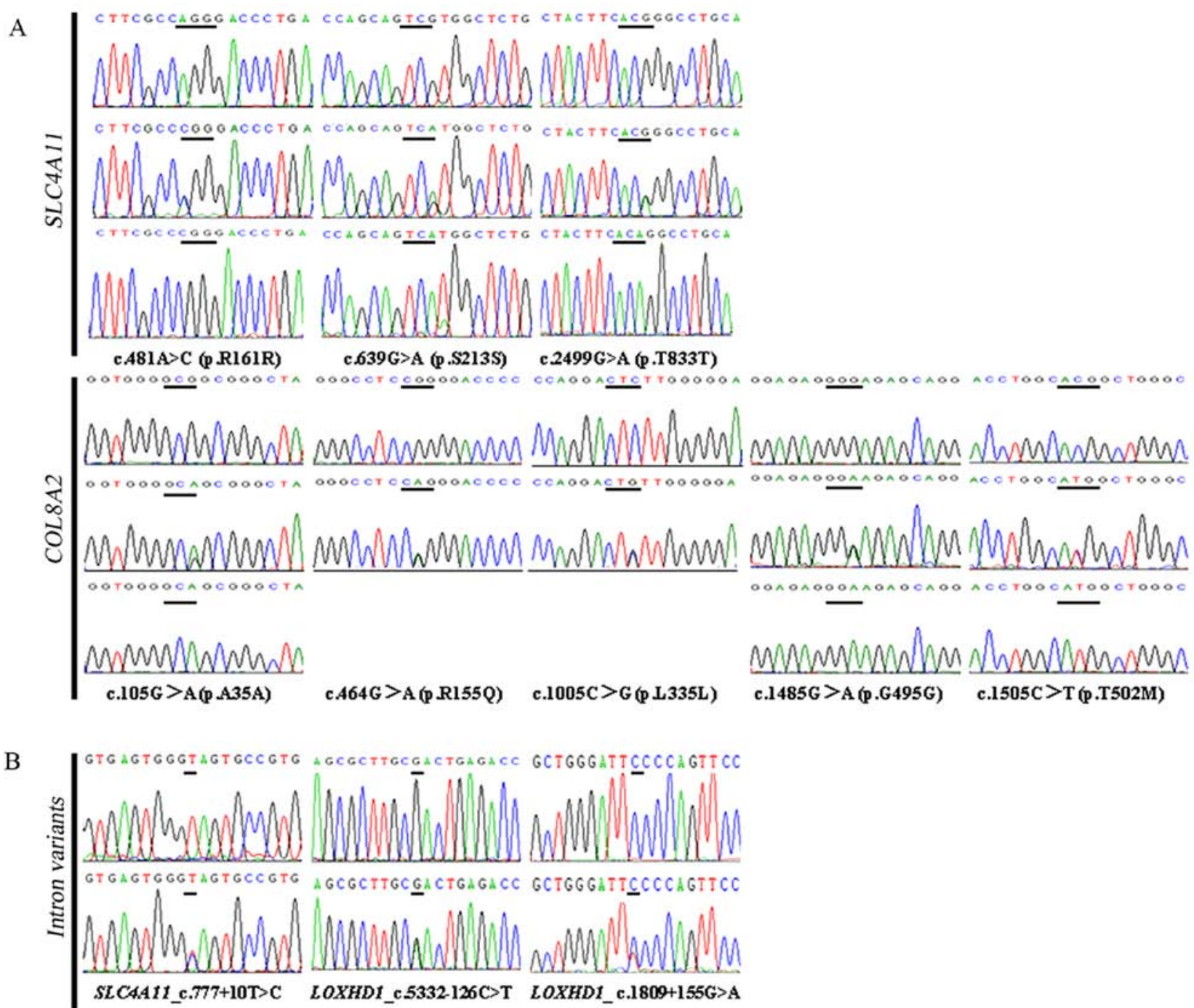

Figure 3. Sequence electropherograms of 8 coding variants detected across the SLC4A11 and COL8A2 genes and 3 intronic variants detected in $S L C 4 A 11$ and LOXHD1 genes. (A) Eight coding variants detected in SLC4A11 and COL8A2 genes. SLC4A11: c.481A >C (p.R161R), c.639G $>$ A (p.S213S) and c.2499G $>$ A (p.T833T); and COL8A2: c.105G >A (p.A35A), c.464G >A (p.R155Q), c.1005C >G (p.L335L), c.1485G >A (p.G495G) and c.1505C >T (p.T502M). Wide-type sequences are shown in the top panel for comparison. The underline marks the variated codon. (B) Three intron variants detected in SLC4A11 and LOXHDI genes. SLC4A11: c.777+10T>C (rs372201212); and LOXHD1: c.5332-126C >T and c.1809+155G >A (both absent from dbSNP). The underline marks the variant nucleotide.

strated that 4 haplotypes (ordered as Indel 1/Indel 2/Indel 3), $\mathrm{I} / \mathrm{I} / \mathrm{I}, \mathrm{D} / \mathrm{I} / \mathrm{I}, \mathrm{D} / \mathrm{D} / \mathrm{I}$ and $\mathrm{D} / \mathrm{D} / \mathrm{D}$, were detected in the present study (Fig. 4B), and these observations were consistent with our bidirectional sequencing results. A schematic illustration of the ZEBI genomic DNA and the position of the 3 continuous indels (Indel 1, Indel 2 and Indel 3) relative to exon 1 is shown in Fig. 4C. Although these 3 indels have not been previously reported in patients with FCD and are absent from dbSNP, they were detected in both the cases and healthy controls $(n \geq 100)($ Table II) (Fig. 2), leading to the conclusion that these 3 indels have no pathogenic correlation with FCD.

Another 2 known dbSNP intron variants were detected in our analysis of the ZEB1 gene (rs220057, MAF: $C=0.2524 / 1264$ and rs220060, MAF: $G=0.0787 / 394)$, both of them were detected in 14 healthy spouses who married into the family (rs220057, 2/28; rs220060, 1/28) (Table II).

Analysis of LOXHD1 gene. Only one known dbSNP intron variant was detected in our analysis of the LOXHDI gene (rs16939650, MAF: T=0.2584/1294), and it was detected in both the cases in this FCD pedigree (7/16) and in the 14 healthy spouses who married into the family (9/28) (Table II). Another 2 intron variants were identified in the cases in this FCD pedigree that have not been previously reported in patients with FCD, namely, c.5332-126C >T and c.1809+155G >A (GenBank reference ID: NM_144612.6) (Table II) (Fig. 2). Both of these variants were absent from dbSNP and were not identified in the 14 unaffected spouses who married into this family $(0 / 28)$ or in the 20 healthy descendants of this family (0/40) (Table II and Fig. 2). Therefore, these 2 variants were further tested in unrelated, ethnically matched controls $(n \geq 100)$, and the results revealed that both of the variants were also absent from the 191 healthy samples we tested (0/382) (Table II). Heterozygous alterations in each variant were only identified in a single case each in this FCD pedigree (c.5332-126C > T was found in II-3, and c.1809+155G $>$ A was found in II-5; Fig. 2) and are likely examples of de novo mutations, the pathological consequences of which are uncertain. 


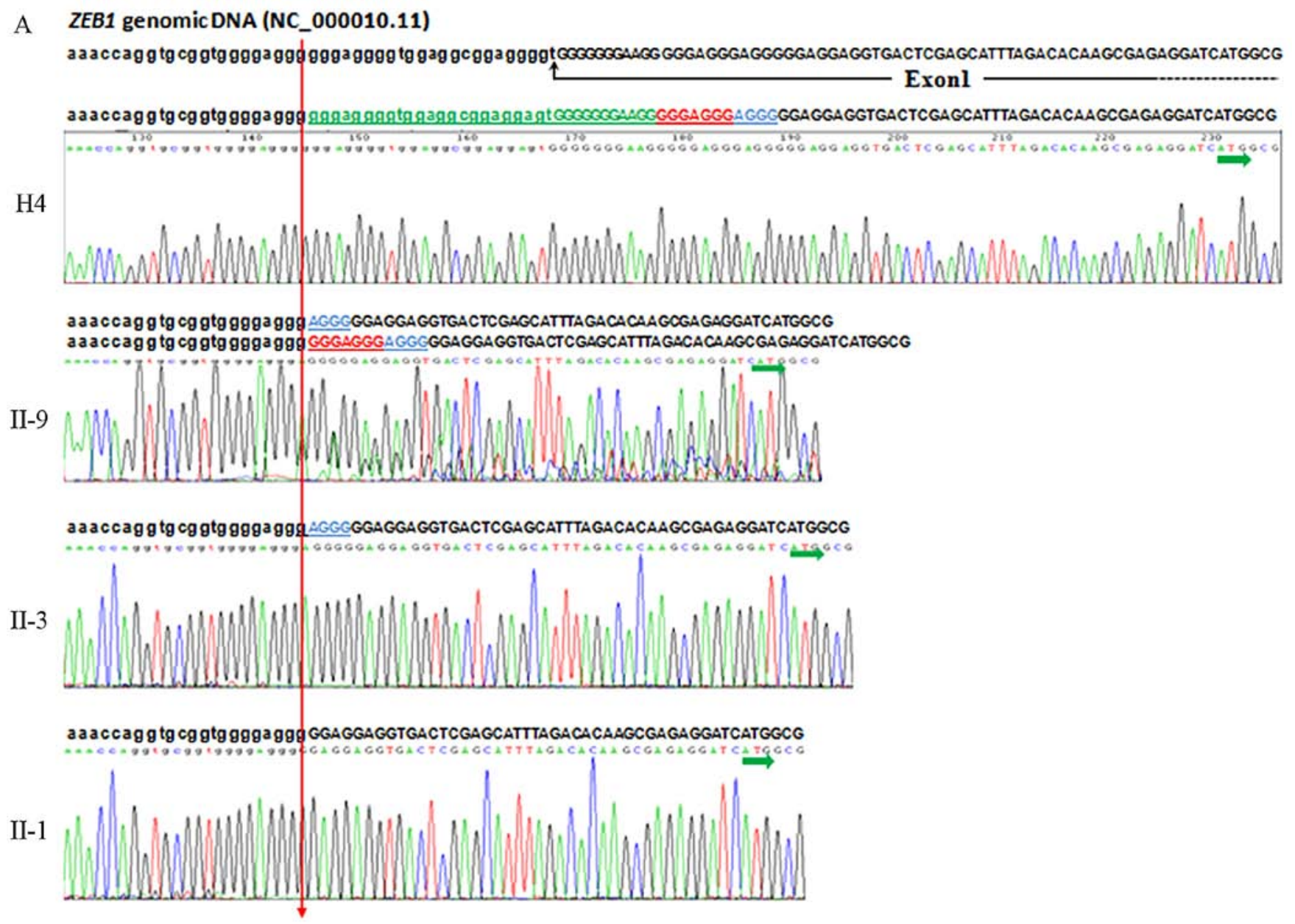

Figure 4. Sequencing analysis of the ZEB1 gene. (A) Sequence electropherograms of PCR products encompassing the 5'-UTR region and exon 1 of the ZEBI genomic DNA. Sequences and sequencing chromatograms of PCR products encompassing 5'-UTR region and exon 1 of the ZEB1 genomic DNA from H4 (healthy control), II-9 (proband), II-3 (FCD case), and II-1 (FCD case) are shown from top to bottom (homozygous is shown in only one sequence, heterozygous is shown in both sequences). ZEB1 genomic DNA sequence (GenBank reference ID: NC_000010.11) was show above (exon and 5'-UTR seqences are depicted by upper and lower case letters, respectively) The breakpoint is indicated by the red arrow. Three indels detected in the present study are indicated in different colors: green for Indel 1,34 bp indel containing 23 bp of the 5'-UTR region and 11 bp 5' end of exon 1 (NM_030751.5: c.-86_-53delinsgggaggggtggaggcggaggggtGGGGGGGAAGG); red for Indel 2, 7 bp (NM_030751.5:c.-52_-46delinsGGGAGGG); blue for Indel 3, 4 bp indel (NM_030751.5:c.-45_-42delinsAGGG). Transcription start site (TSS) is indicated by a horizontal green arrow underneath ATG. The numbering system used for sequence variations is based on cDNA sequence with +1 corresponding to the A of the ATG TSS (GenBank Reference ID: NM_030751.5). FCD, Fuchs corneal dystrophy.

Analysis of COL8A2 gene. Five known dbSNP variants were detected in our analysis of the COL8A2 gene, including 3 synonymous variants, p.A35A (rs57985157, MAF: T=0.0966/484), p.L335L (rs79833067, MAF: $\mathrm{C}=0.0413 / 207)$ and p.G495G (rs35495320, MAF: $\mathrm{T}=0.1815 / 909)$, and 2 missense variants, p.R155Q (rs75864656, MAF: $\mathrm{T}=0.0377 / 188)$ and p.T502M (rs117860804, MAF: $A=0.0587 / 294$ ) (Table II) (Fig. 3). Four of these SNP coding variants from dbSNP (p.A35A, p.G495G, p.R155Q and p.T502M) have been reported in patients with FCD and unaffected individuals previously (21-23) and were present in both the affected members of this FCD pedigree (p.A35A, 5/16; p.G495G, 12/16; p.R155Q, 3/16; and p.T502M, 7/16) and in the 14 healthy spouses who married into the family (p.A35A, 12/28; p.G495G, 19/28; p.R155Q, 3/28; and p.T502M, 6/28) (Table II) (Fig. 2), as well as in the unrelated, ethnically matched, healthy control subjects
(p.A35A, 128/364; p.G495G, 202/364; p.R155Q, 23/364; and p.T502M, 79/364) (Table II).

In addition, the synonymous variant p.L335L, which has been previously reported in 2 patients with posterior polymorphous corneal dystrophy (PPCD; MIM 122000) (18), was present in 10 unaffected family members, 6 of whom were unrelated spouses who married into this family, and none of them displayed any clinical features of FCD (Table II) (Fig. 2). Furthermore, the finding of this synonymous variant in 182 healthy control individuals (p.L335L, 88/364) (Table II), along with the absence of the p.L335L synonymous change in any of the 8 affected individuals in this Chinese FCD family (Table II) (Fig. 2) and the detection of this silent variant in 1 out of 116 healthy controls previously reported (18), leads to the conclusion that this substitution is a known polymorphism (dbSNP: rs79833067), and it has no association with FCD. 
B

Exon1

$\mathrm{I} / \mathrm{I} / \mathrm{I}$
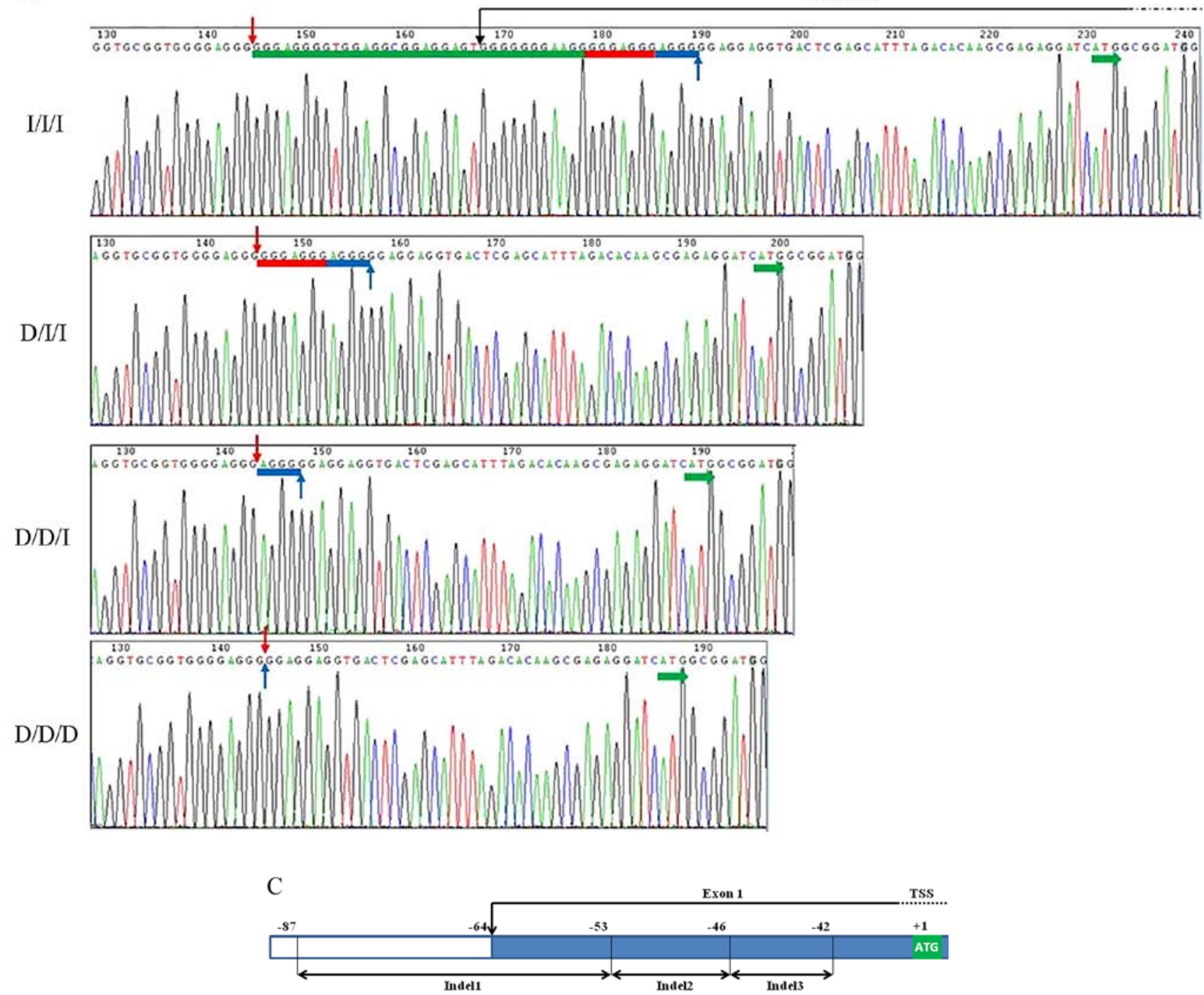

Figure 4. Continued. Sequencing analysis of ZEB1 gene. (B) DNA sequencing results of the four haplotypes subcloned into pZeroBack/blunt vector. Three indels were underlined in different colors: green for Indel 1; red for Indel 2; and blue for Indel 3. Sequencing chromatograms of 4 haplotypes (ordered as Indel 1/Indel $2 /$ Indel 3), I/I/I, D/I/I, D/D/I, D/D/D, are shown from top to bottom. The 5' and 3' boundaries of indel are shown by a vertical red and a blue arrow, respectively. TSS is indicated by a horizontal green arrow underneath ATG. (C) Schematic illustration of the ZEB1 genomic DNA and distribution of 3 continuous Indels (Indel 1, 2 and 3) relative to exon 1. The numbering system used for sequence variations is based on cDNA sequence with +1 corresponding to the A of the ATG TSS (GenBank Reference ID: NM_030751.5). FCD, Fuchs corneal dystrophy.

TCF4 genotype. The PCR products of the TCF4 gene, which contains 7 previously reported SNPs significantly associated with LO FCD, were sequenced. An analysis of an intronic SNP in the TCF4 gene, rs613872 (MAF: $\mathrm{G}=0.0697 / 348$ ), the risk allele $(\mathrm{G})$ that has been identified to be significantly associated with FCD among Europeans through genome-wide association studies (GWAS) (14), revealed that the risk allele $(G)$ was not present in any subject in our FCD pedigree $(0 / 84 ; 84$ refers to the total number of chromosomes detected for the 42 members of the pedigree in whom DNA collection and genetic analysis were performed), and only one individual was heterozygous for the risk allele (G) out of the 191 unrelated healthy controls we tested (1/382) (Table II). This result was consistent with a previous study in which rs613872 was not present in Singaporean Chinese (15). The detection of 2 other SNPs (rs17089887, MAF: $C=0.1689 / 846$ and rs17089925, MAF: $T=0.1569 / 786)$, which had been found to be significantly associated with FCD in Singaporean Chinese (15), revealed that only 3 out of 8 cases carried the heterozygous risk allele (C) of rs17089887 (3/16) and that only 1 out of 8 cases carried the heterozygous risk allele (T) of rs17089925 (1/16). Both of these risk alleles were also present in the 14 healthy individuals who married into this family (rs17089887: 6/28; rs17089925: 10/28) (Table II). The analysis of another 3 SNPs that exhibited a marginal association with FCD in Singaporean Chinese (rs1348047, MAF: $T=0.2780 / 1392$; rs1452787, MAF: $\mathrm{G}=0.2708 / 1356$; and rs2123392, MAF: $\mathrm{C}=0.3005 / 1504)$ (15) revealed that 7 out of 8 cases carried the risk allele ( $\mathrm{T}$ ) of rs 1348047 ( 3 homozygous and 4 heterozygous for the risk allele, 10/16), 7 out of 8 cases carried the risk allele $(\mathrm{G})$ of rs1452787 (1 homozygous and 6 heterozygous for the risk allele, 8/16), and all 8 cases carried the risk allele (C) of rs2123392 (5 homozygous and 3 heterozygous for the risk allele, 13/16). While these 3 risk alleles were also present in the 14 healthy individuals who 
A
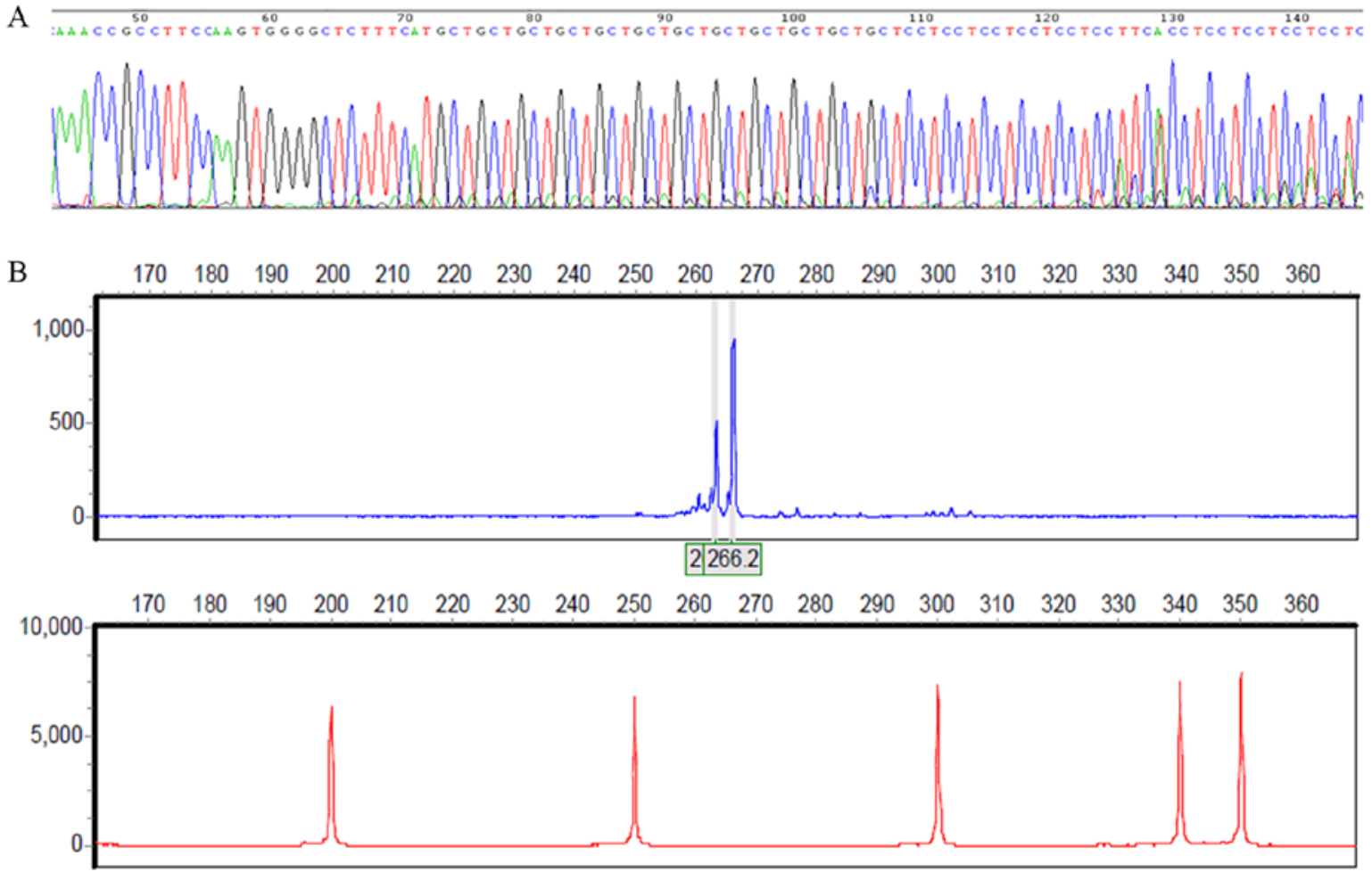

Figure 5. Analysis of TGC trinucleotide repeat expansion (rs193922902) of TCF4. (A) Sanger DNA sequencing of DNA samples of proband showed heterozygous for allele $(\mathrm{TGC})_{11}$ and (TGC) $)_{12}$. (B) STR analysis of PCR amplicons of proband verified heterozygous for allele $(\mathrm{TGC})_{11}$ and $(\mathrm{TGC})_{12}$.

married into this family (rs1348047, 16/28; rs1452787, 14/28; and rs2123392, 11/28) (Table II), none of these 6 SNPs from dbSNP co-segregated with the disease.

One TGC trinucleotide repeat expansion (rs193922902) of TCF4, a repeat length $>50$ of which is known to play a pathogenic role in the majority of FCD cases and is considered to be a predictor of disease risk (16), was also detected in the present study. The direct sequencing of the proband indicated that it contained one 11- and one 12-repeat allele (Fig. 5A), and this result was further confirmed by STR analysis (Fig. 5B). The expanded repeat was not found in any of the subjects in our pedigree (0/84) (Table II), which indicated that this TGC trinucleotide expansion did not play a pathogenic role in this specific FCD family.

\section{Discussion}

To date, progress toward identifying the underlying genetic components of FCD has been limited to the analysis of a few genes, including SLC4A11, ZEB1, LOXHD1 and COL8A2 $(4,10,12,13,20,21)$. Several genome-wide linkage studies have additionally provided evidence of linkage to several different chromosomal loci, namely FCD1, FCD2, FCD3 and FCD4, on chromosomes 13, 18, 5 and 9, respectively $(10,24-$ 26), that appear to influence familial FCD. Thus, it appears that locus heterogeneity may exist for FCD, whereby mutations in several genes on different chromosomes may produce a common disease phenotype. Significant progress toward understanding non-familial FCD was made using GWAS. Baratz et al identified an SNP on chromosome 18q21, rs613872, in an intron of a gene encoding (TCF4) (MIM 602272) and showed a significant genome-wide association with FCD susceptibility in Europeans (14). This finding was further validated by Li et al (27) in another independent study. Although rs613872 was not found to be present in Singaporean Chinese FCD subjects, 2 other SNPs (rs17089887 and rs17089925) (15) and one TGC trinucleotide repeat expansion (rs193922902) (16) of the TCF4 gene were reported to be significantly associated with FCD in the Chinese subjects.

Despite these insights, knowledge regarding the genetic basis of FCD in the China mainland population has remained limited, possibly due to the varying prevalence of FCD in different ethnic populations. The prevalence of FCD is generally considered to be approximately $4 \%$ in individuals above 40 years of age in the United States and accounts for the second most common indication for corneal transplants performed in the United States in patients over the age of 60 years $(28,29)$. The prevalence of FCD in other countries and areas has been confirmed by studies that have examined indications for PK at various institutions worldwide; prevalences of 15.4, 7.1 and $4.7 \%$ have been reported in populations from the UK (30), Singapore (31) and Australia (32), respectively, while studies in China suggest a relatively lower prevalence of FCD, namely, $4.5 \%$ in Taiwan (33) and $<3.9 \%$ in both the northern and eastern mainland of China $(34,35)$. Combined with clinical experience in the US that suggests a significantly decreased prevalence of FCD among individuals of African-American, Latin-American, or Asian origin, a greater understanding of the genetic basis of FCD in patients of different ethnic origins will shed more light on the molecular mechanisms of the disease.

To the best of our knowledge, the present study is the first study on a Chinese mainland population to focus on the genetic 
basis of the multi-generational Chinese pedigree with LO FCD that was previously reported by our group (36). In the present study, we performed a sequence analysis of the SLC4A11,ZEB1, LOXHD1, COL8A2 and TCF4 genes in this LO FCD pedigree.

Screening of the SLC4A11 gene revealed 14 known dbSNP variants; among these, an intronic variant, is a known SNP from dbSNP (rs372201212, MAF: $\mathrm{G}=0.0014 / 7$ ), its minor allele $(\mathrm{G})$ was detected in 4 of 8 affected members of this FCD pedigree, II-1, II-5, III-9 (II-1's daughter), and III-19 (II-5' son) (4/16), and 3 of 20 healthy descendants in this family, III-3 (II-1's son, III-9's older brother), IV-4 (II-1's granddaughter, III-3's daughter) and IV-16 (II-5's grandson, III-19's son) (3/40). Although this variant was not identified in any unaffected individuals who married into this family $(0 / 28)$ or in the unrelated healthy controls $(0 / 382)$, it may not be considered pathogenic as it did not co-segregate with the disease in this FCD pedigree. However, we cannot rule out the possibility that this variant has an association with FCD; if we consider the late onset of the disease and the fact that IV- 4 and IV-16 were 20 and 14 years old, respectively, when the blood samples were collected in 2009, the disease status in these younger individuals is uncertain, as they may not have been old enough to manifest the disorder and may not clinically exhibit the disease, suggesting that this variant may be correlated with FCD in this family. Further analysis of this known SNP from dbSNP (rs372201212) in the SLC4A11 gene in larger numbers of Chinese patients with FCD may elucidate the significance of this gene in corneal endothelial dystrophies.

Similarly, 2 intron variants of the $L O X H D 1$ gene were identified in this FCD pedigree: c.5332-126C $>\mathrm{T}$ and c. $1809+155 \mathrm{G}>\mathrm{A}$ (GenBank reference ID: NM_144612.6). These 2 variants have not been previously reported in FCD patients and were absent from dbSNP. Neither of these variants was identified in the unaffected family members or in the healthy controls $(n \geq 100)$. As these variants were each found in only a single case in this FCD pedigree (c.5332-126C $>\mathrm{T}$ in II-3, and c.1809+155G $>\mathrm{A}$ in II-5), they are likely examples of de novo mutations.

ZEB1 is a zinc finger E-box binding homeobox 1 gene (MIM 189909) and is also known as human zinc finger TCF8, which maps to chromosome 10p11.2, comprises 9 exons and encodes a transcription factor that is organized into multiple functional domains starting with $\mathrm{N}$-terminal zinc finger clusters (172-292), followed by a homeodomain (581-640), a repression domain (754-901), C-terminal zinc finger clusters (905-981) and an acidic activation domain (1011-1124) (37). The structure of $Z E B 1$ allows for a wide range of functions as each zinc finger has different DNA-binding specificities and effects on gene expression (38). Mutations in the ZEBI transcripts have been shown to produce a wide range of ocular phenotypes (39). It was estimated that changes in this gene may account for approximately 50\% of all PPCD cases (40), and its mutations also account for LO FCD (12). Through ZEB1 screening, we identified 3 continuous indels located at the junction of the 5'-UTR and the adjacent $5^{\prime}$ end of exon 1 of the ZEB1 gene in the cases in this FCD pedigree, and these 3 indels covered the region from -86 to -42 (numbering system based on the cDNA sequence with +1 corresponding to the A of the ATG TSS in the Ref Seq: NM_030751.5). A schematic illustration of the ZEB1 genomic DNA and the location of these 3 continuous indels relative to exon 1 is shown in Fig. $4 \mathrm{C}$, and these 3 continuous indels, including 34 bp Indel 1 (containing $23 \mathrm{bp}$ of the 5'-UTR region and $11 \mathrm{bp}$ of the 5' end of exon 1), $7 \mathrm{bp}$ Indel 2 (containing $7 \mathrm{bp}$ of exon 1), and 4 bp Indel 3 (containing $4 \mathrm{bp}$ of exon 1). In addition, according to the UCSC Genome Browser (http://genome.ucsc.edu/cgi-bin/hgGateway?hgsid= 488683917_eMaJPXBAmxFX5D7tqTNSeva4dT39), the bases affected by these 3 indels are relatively well conserved through evolution and also lie within transcription factor binding sites, and these regions are also enriched with H3K27AC, which is often found near active regulatory elements. In the case of Indel 1, the splice site variation affects the first splice site and may likely cause mis-splicing of the pre-mRNA transcript. This variation would lead to either exon skipping or intron retention, which would consequently result in an altered protein structure. Therefore, we hypothesized that a different haplotype of ZEBI will alter the mRNA structure or influence splicing efficiency. Further studies are needed to determine what effect, if any, these indels may have on ZEB1 gene function and FCD pathogenesis; however, the presence of these 3 indels in the 14 healthy spouses who married into this family, the unaffected family members, and the healthy controls $(\mathrm{n} \geq 100)$ suggests that these 3 indels are not likely to be pathogenic.

In the screening of the COL8A2 gene, neither of the previously reported pathogenic mutations of COL8A2 (p.L450W and p.Q455K or Q455V) $(4,21,23)$ was observed in this family, and none of the novel mutations were identified in the COL8A2 gene in this LO FCD pedigree of Chinese descent. Our results are not surprising, as several studies have been published demonstrating a lack of COL8A2 mutations in LO FCD (22).

Variations in candidate genes of FCD, deemed pathogenic on the basis of their absence in control chromosomes, were later identified as common polymorphisms in other ethnic populations (21-23), due to the fact that frequency of gene variant may depend greatly on the population screened. The MAF of 8 coding variants across SLC4A11 (p.R161R, p.S213S and p.T833T) and COL8A2 (p.A35A, p.R155Q, p.L335L, p.G495G and p.T502M) genes in healthy controls with Chinese ancestry $(n \geq 100)$ were compared with MAF data from the 1000 Genomes database (Table II). The statistical analysis demonstrated that 4 MAF of COL8A2 gene (p.A35A, p.L335L, p.G495G and p.T502M) in Chinese healthy controls tested in the present study were all significantly higher than the data from 1000 Genomes $(\mathrm{P}<0.01)$ (Table II), indicated that these varations were rare in occidental populations (21), which may account for the absence of these minor allele distribution in control chromosomes in previous study (21-23).

Since the publication of the initial GWAS results indicating a significant association of an intronic SNP in TCF4, rs613872, with FCD (14), several studies across different cohorts from diverse populations have demonstrated that polymorphisms near TCF4 were consistently linked to an increased prevalence of FCD $(15,27)$. These SNPs of TCF4 were detected in this Chinese LO FCD pedigree, and the analysis revealed that the SNP rs613872, which is most highly associated with FCD in Caucasians, was not found to be present in this Chinese FCD family (0/84), and only one individual carrying the heterozygous variant of rs613872 was detected in the healthy controls (1/382), the MAF of healthy controls tested in the present study is significantly lower when compared with the data from 1000 Genomes $(\mathrm{P}<0.01)$ (Table II). This result is 
consistent with previous research (15), in which rs613872 was not found to be present in Chinese FCD subjects, as well as with the data from the Human Genome Diversity Project, in which the minor (risk) allele, G, of rs613872 was found to be rare in populations from Africa, Eastern Asia, and Central and South America and more frequent in European, Middle Eastern, and Southern Asian populations (41). Two other SNPs (rs17089887 and rs17089925), which have been reported to be significantly associated with FCD in Singaporean Chinese (15), and a TGC trinucleotide repeat expansion (rs193922902) of TCF4, a repeat length $>50$ of which plays a pathogenic role in the majority of FCD cases (16), were also detected in this Chinese LO FCD pedigree. The results revealed that none of these 3 SNPs co-segregated with the disease. Therefore, we investigated whether the three SNPs that were marginally associated with FCD in Singaporean Chinese (rs1348047, rs1452787 and rs2123392) (15) had some association with FCD in this Chinese LO FCD pedigree, and the results revealed that all three risk alleles were present in both the 8 cases and the 14 healthy individuals who married into this family. This finding led to the conclusion that none of these known SNPs provide strong evidence of pathogenesis in this specific muti-generational LO FCD Chinese family; however, because only seven fragments containing 7 SNPs were sequenced in the present study, we still cannot rule out the possibility that additional variants in other regions of the TCF4 gene that were not assessed in the present study may be present that could confer phenotypic changes.

In conclusion, to identify and exclude known mutations and SNPs associated with FCD, we screened our LO FCD pedigree for all known exons and adjacent splice sites in the previously reported FCD genes that were associated with either LO FCD (SLC4A11, ZEB1, LOXHD1 and TCF4) or EO FCD (COL8A2). Twenty-seven variants (including 22 known dbSNP variants and 5 variants absent from dbSNP) were detected. None of these variants provided strong evidence of pathogenesis, making it unlikely that SNPs or mutations in them caused FCD in this specific pedigree. The possibility of pathogenic changes occurring within the promoter, intronic, or untranslated noncoding regions of these genes playing a role in the pathogenesis of FCD has not been excluded in this study. The fact that we did not detect any pathogenic variants in these genes in our pedigree is likely a combination of the fact that these genes carry a low genetic load in FCD and that we screened only one LO FCD pedigree, a small sample that is underpowered for detecting variants that occur at relatively low frequencies. Clearly, a genome-wide linkage scan to identify linkage to one of the previously described FCD loci or to identify a novel locus for FCD will need to be performed in this multi-generational Chinese pedigree with LO FCD. Our observation, nevertheless, expands the current knowledge regarding the genetic status of Chinese ancestry patients with FCD.

\section{Acknowledgements}

The authors would like to thank all the family members and other people who generously participated in the study. The study was supported by the joint grands from the Yunnan Scientific and Technology Committee and Kunming Medical University, P.R. China (no. 2012FB090).

\section{References}

1. Fuchs E: Fuchs E Dystrophia epithelialis corneae. Albrecht Von Graefes Arch Klin Exp Ophthalmol 76: 478-508, 1910.

2. Adamis AP, Filatov V, Tripathi BJ and Tripathi RC: Fuchs' endothelial dystrophy of the cornea. Surv Ophthalmol 38: 149-168, 1993.

3. Krachmer JH, Purcell JJ Jr, Young CW and Bucher KD: Corneal endothelial dystrophy. A study of 64 families. Arch Ophthalmol 96: 2036-2039, 1978.

4. Gottsch JD, Sundin OH, Liu SH, Jun AS, Broman KW, Stark WJ, VitoEC, Narang AK, Thompson JM and Magovern M: Inheritance of a novel COL8A2 mutation defines a distinct early-onset subtype of fuchs corneal dystrophy. Invest Ophthalmol Vis Sci 46: 1934-1939, 2005.

5. Waring GO III, Bourne WM, Edelhauser HF and Kenyon KR: The corneal endothelium. Normal and pathologic structure and function. Ophthalmology 89: 531-590, 1982.

6. Bergmanson JP, Sheldon TM and Goosey JD: Fuchs' endothelial dystrophy: A fresh look at an aging disease. Ophthalmic Physiol Opt 19: 210-222, 1999.

7. Thompson RW Jr, Price MO, Bowers PJ and Price FW Jr: Long-term graft survival after penetrating keratoplasty. Ophthalmology 110: 1396-1402, 2003.

8. Anshu A, Price MO, Tan DT and Price FW Jr: Endothelial keratoplasty: a revolution in evolution. Surv Ophthalmol 57: 236-252, 2012.

9. Ham L, Dapena I, van Luijk C, van der Wees J and Melles GR: Descemet membrane endothelial keratoplasty (DMEK) for Fuchs endothelial dystrophy: review of the first 50 consecutive cases. Eye (Lond) 23: 1990-1998, 2009.

10. Riazuddin SA, Vithana EN, Seet LF, Liu Y, Al-Saif A, Koh LW, Heng YM, Aung T, Meadows DN, Eghrari AO, et al: Missense mutations in the sodium borate cotransporter SLC4A11 cause lateonset Fuchs corneal dystrophy. Hum Mutat 31: 1261-1268, 2010.

11. Vithana EN, Morgan P, Sundaresan P, Ebenezer ND, Tan DT, Mohamed MD, Anand S, Khine KO, Venkataraman D, Yong VH, et al: Mutations in sodium-borate cotransporter SLC4A11 cause recessive congenital hereditary endothelial dystrophy (CHED2). Nat Genet 38: 755-757, 2006.

12. Riazuddin SA, Zaghloul NA, Al-Saif A, Davey L, Diplas BH, Meadows DN, Eghrari AO, Minear MA, Li YJ, Klintworth GK, et al: Missense mutations in TCF8 cause late-onset Fuchs corneal dystrophy and interact with FCD4 on chromosome 9p. Am J Hum Genet 86: 45-53, 2010.

13. Riazuddin SA, Parker DS, McGlumphy EJ, Oh EC, Iliff BW, Schmedt T, Jurkunas U, Schleif R, Katsanis N and Gottsch JD: Mutations in LOXHD1, a recessive-deafness locus, cause dominant late-onset Fuchs corneal dystrophy. Am J Hum Genet 90: 533-539, 2012.

14. Baratz KH, Tosakulwong N, Ryu E, Brown WL, Branham K, Chen W, Tran KD, Schmid-Kubista KE, Heckenlively JR, Swaroop A, et al: E2-2 protein and Fuchs's corneal dystrophy. N Engl J Med 363: 1016-1024, 2010.

15. Thalamuthu A, Khor CC, Venkataraman D, Koh LW, Tan DT, Aung T, Mehta JS and Vithana EN: Association of TCF4 gene polymorphisms with Fuchs' corneal dystrophy in the Chinese. Invest Ophthalmol Vis Sci 52: 5573-5578, 2011.

16. Wieben ED, Aleff RA, Tosakulwong N, Butz ML, Highsmith WE, Edwards AO and Baratz KH: A common trinucleotide repeat expansion within the transcription factor 4 (TCF4, E2-2) gene predicts Fuchs corneal dystrophy. PLoS One 7: e49083, 2012.

17. Gottsch JD, Zhang C, Sundin OH, Bell WR, Stark WJ and Green WR: Fuchs corneal dystrophy: Aberrant collagen distribution in an L450W mutant of the COL8A2 gene. Invest Ophthalmol Vis Sci 46: 4504-4511, 2005.

18. Yellore VS, Rayner SA, Emmert-Buck L, Tabin GC, Raber I, Hannush SB, Stulting RD, Sampat K, Momi R, Principe AH and Aldave AJ: No pathogenic mutations identified in the COL $8 A 2$ gene or four positional candidate genes in patients with posterior polymorphous corneal dystrophy. Invest Ophthalmol Vis Sci 46: 1599-1603, 2005.

19. Hemadevi B, Srinivasan M, Arunkumar J, Prajna NV and Sundaresan P: Genetic analysis of patients with Fuchs endothelial corneal dystrophy in India. BMC Ophthalmol 10: 3, 2010.

20. Vithana EN, Morgan PE, Ramprasad V, Tan DT, Yong VH, Venkataraman D, Venkatraman A, Yam GH, Nagasamy S, Law RW, et al: SLC4A11 mutations in Fuchs endothelial corneal dystrophy. Hum Mol Genet 17: 656-666, 2008. 
21. Biswas S, Munier FL, Yardley J, Hart-Holden N, Perveen R Cousin P, Sutphin JE, Noble B, Batterbury M, Kielty C, et al: Missense mutations in COL8A2, the gene encoding the alpha2 chain of type VIII collagen, cause two forms of corneal endothelial dystrophy. Hum Mol Genet 10: 2415-2423, 2001.

22. Kobayashi A, Fujiki K, Murakami A, Kato T, Chen LZ, Onoe H, Nakayasu K, Sakurai M, Takahashi M, Sugiyama K and Kanai A: Analysis of COL8A2 gene mutation in Japanese patients with Fuchs' endothelial dystrophy and posterior polymorphous dystrophy. Jpn J Ophthalmol 48: 195-198, 2004.

23. Mok JW, Kim HS and Joo CK: Q455V mutation in COL8A2 is associated with Fuchs' corneal dystrophy in Korean patients. Eye (Lond) 23: 895-903, 2009.

24. Sundin OH, Jun AS, Broman KW, Liu SH, Sheehan SE, Vito EC Stark WJ and Gottsch JD: Linkage of late-onset Fuchs corneal dystrophy to a novel locus at 13pTel-13q12.13. Invest Ophthalmol Vis Sci 47: 140-145, 2006.

25. Sundin OH, Broman KW, Chang HH, Vito EC, Stark WJ and Gottsch JD: A common locus for late-onset Fuchs corneal dystrophy maps to 18q21.2-q21.32. Invest Ophthalmol Vis Sci 47: 3919-3926, 2006.

26. Riazuddin SA, Eghrari AO, Al-Saif A, Davey L, Meadows DN, Katsanis N and Gottsch JD: Linkage of a mild late-onset phenotype of Fuchs corneal dystrophy to a novel locus at 5q33.1-q35.2. Invest Ophthalmol Vis Sci 50: 5667-5671, 2009.

27. Li Y-J, Minear MA, Rimmler J, Zhao B, Balajonda E, Hauser MA Allingham RR, Eghrari AO, Riazuddin SA, Katsanis N, et al: Replication of TCF4 through association and linkage studies in late-onset Fuchs endothelial corneal dystrophy. PLoS One 6: e18044, 2011

28. Klintworth GK: Corneal dystrophies. Orphanet J Rare Dis 4: 7, 2009.

29. Mannis MJ, Holland EJ, Beck RW, Belin MW, Goldberg MA, Gal RL, Kalajian AD, Kenyon KR, Kollman C, Ruedy KJ, et al; Cornea Donor Study Group: Cornea Donor Study Group: Clinical profile and early surgical complications in the Cornea Donor Study. Cornea 25: 164-170, 2006.

30. Rahman I, Carley F, Hillarby C, Brahma A and Tullo AB: Penetrating keratoplasty: indications, outcomes, and complications. Eye (Lond) 23: 1288-1294, 2009.
31. Tan DT, Janardhanan P, Zhou H, Chan YH, Htoon HM, Ang LP and Lim LS: Penetrating keratoplasty in Asian eyes: The Singapore Corneal Transplant Study. Ophthalmology 115: 975-982.e1, 2008.

32. No authors listed: The Australian Corneal Graft Registry: 1990 to 1992 report. Aust N Z J Ophthalmol 21 (Suppl 2): 1-48, 1993.

33. Chen WL, Hu FR and Wang IJ: Changing indications for penetrating keratoplasty in Taiwan from 1987 to 1999. Cornea 20: 141-144, 2001.

34. Xie L, Song Z, Zhao J, Shi W and Wang F: Indications for penetrating keratoplasty in north China. Cornea 26: 1070-1073, 2007.

35. Zhang $\mathrm{C}$ and $\mathrm{Xu} \mathrm{J}$ : Indications for penetrating keratoplasty in East China, 1994-2003. Graefes Arch Clin Exp Ophthalmol 243: 1005-1009, 2005.

36. Huo L, Hui T, Tao S, Hong D and Yan X: A pedigree of Fuchs Corneal Dystrophy. Zhonghua Yi Xue Yi Chuan Xue Za Zhi 27: 231-232, 2010 (In Chinese).

37. Ikeda K, Halle JP, Stelzer G, Meisterernst M and Kawakami K: Involvement of negative cofactor NC2 in active repression by zinc finger-homeodomain transcription factor AREB6. Mol Cell Biol 18: 10-18, 1998.

38. Ikeda K, Kawakami K, Stelzer G, Meisterernst M and Kawakami K: DNA binding through distinct domains of zinc-finger-homeodomain protein AREB6 has different effects on gene transcription. Eur J Biochem 233: 73-82, 1995.

39. Moroi SE, Gokhale PA, Schteingart MT, Sugar A, Downs CA, Shimizu S, Krafchak C, Fuse N, Elner SG, Elner VM, et al: Clinicopathologic correlation and genetic analysis in a case of posterior polymorphous corneal dystrophy. Am J Ophthalmol 135: 461-470, 2003.

40. Krafchak CM, Pawar H, Moroi SE, Sugar A, Lichter PR, Mackey DA, Mian S, Nairus T, Elner V, Schteingart MT, et al: Mutations in TCF8 cause posterior polymorphous corneal dystrophy and ectopic expression of COL4A3 by corneal endothelial cells. Am J Hum Genet 77: 694-708, 2005.

41. Kent WJ, Sugnet CW, Furey TS, Roskin KM, Pringle TH, Zahler AM and Haussler D: The human genome browser at UCSC. Genome Res 12: 996-1006, 2002. 